large osmium tetroxide-pyridine molecule, and lead to slower addition.

Johnson Chemical Laboratories,

G. M. BADGER

University of Adelaide.

Dec. 10 Pullman, B., C.R. Acad. Sci., Paris, 222, 1396 (1946). See also
Daudel, R., and Martin, M., Bull. Soc. chim., 15, 559 (1948). Ketelaar, J. A. A., and van Oostcrhout, G. W., Rec. trav. chim., 65,

${ }^{3}$ Pullman, A., C.R. Acad. Sci., Paris, 224, 1354 (1947).

4 Badger, G. M., J. Chem. Soc., 456 (1948) and unpublished work.

5 Badger, G. M., J. Chem. Soc., 535 (1941). Everett, J. L., and Kon, G. A. R., J. Chem. Soc., 1601 (1948).

${ }^{8}$ Fulton, J. D., and Robinson, R., J. Chem. Soc., 200 (1939).

'Böeseken, J., and Stuurman, J., Rec. trav. chim., 56, 1034 (1937)

Paal, C., and Schiedewitz, H., Ber., 63, 766 (1930). Birks, A. M.

and Wright, G. F., J. Amer, Chem. Soc., 62, 2412 (1940).

Ferguson, L. N., Chem. Rev., 43, 419 (1948).

\section{Serum Potassium by Internal Standard Flame Photometry}

Frame photometric analysis ${ }^{1}$ of cations in biological fluids and tissues is, because of its simplicity, rapidity and greater accuracy, replacing laborious chemical procedures. The vaporization of alkali metal solutions in constant amount per minute into a controlled lowtemperature air-acetylene flame produces simple emission spectra, the light intensities of which, measured photo-electrically after slit isolation of the most sensitive line spectrum for the particular element (potassium red flame at $7665 \mathrm{~A}$.), are practically proportional to their concentrations for low concentrations ${ }^{2}$.

Absolute light-intensity measurements are subject to errors, due to variable viscosity, surface tension and composition of samples affecting the rate of atomization and the character of the flame ${ }^{1,3}$. However, the addition of lithium to all solutions analysed provides a means of internal standard compensation whereby light-intensity ratios are determined. Variations are thus considerably reduced, and recoveries with an average error of \pm 2 per cent are obtained for sodium and potassium, using a Perkin-Elmer 52A flame photometer ${ }^{2}$.

A notable exception occurs in the estimation of serum potassium, where sodium is present in concentration ( \pm 145 m.eq./litre) some twenty-five times that of potassium ( \pm 5 m.eq./litre). Due to the phenomenon of mutual excitation, more luminous energy per m.eq. potassium is produced in the presence of a large excess of sodium than from potassium in pure solution (sodium per se produces no spectral emission at the potassium wave-length). This enhanced excitation, not completely compensated for by the added lithium, is found to be fairly uniform over a range of 20-50 Na: $1 \mathrm{~K}$ for potassium calibration solutions covering a $1: 5$ to $1: 20$ serum dilution :

Effect of sodium added to potassium solutions (potassium 0-2 m.eq./ litre at $0 \cdot 25$ intervals)

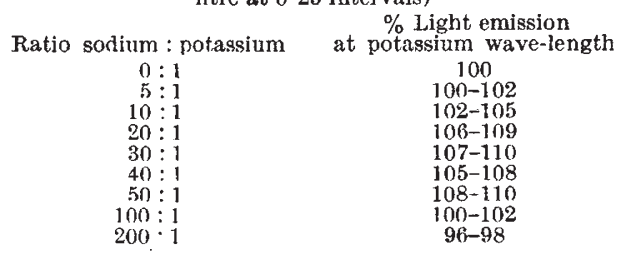

Hence reference to a potassium calibration curve to which sodium is added, depending on the serum dilution for estimation, in the equivalent of 145 m.eq./ litre, will cover a serum-sodium range from 100 to $180 \mathrm{~m}$.eq./litre and so provide adequate compensation for pathological variations of serum sodium.

Recovery from standard solutions (combinations of 4, 5, 6 m.eq. potassium per litre with 100, 125, 150, 175 m.eq. sodium per litre) and of potassium added to serum samples yields average recovery errors of $\pm 2 \cdot 3$ per cent for flame photometric analysis and $\pm \mathbf{4} \cdot \mathbf{2}$ per cent by chemical estimation. Serum potassium estimations by flame photometry, using dry ashing or deproteinizing techniques, give slightly lower results than the chemical method of Cumings 4 .

Recovery and serum values are 5-10 per cent too high by flame photometric analysis using a pure potassium calibration curve.

Department of Physiology,

University of the Witwatersrand Medical School, Johannesburg.

Dec. 28.

${ }^{1}$ Berry, J. W., Chappell, D. G., and Barnes, R. B., Indust. Chem. Eng., Anal. Ed., 18, 19 (1946).

${ }^{2}$ Bernstein, R. E., S.A. J. Med. Sci., 14, 163 (1949)

${ }^{3}$ Parks, T. D., Johnson, H. O., and Lykken, L., Anal. Chem., 20, 822 (1948).

Cumings, J. N., J. Clin. Path., 1, 173 (1948).

\section{Antibiotics in the Treatment of Amœbiasis}

ReCent work by MeVay, Laird and Sprunt ${ }^{1}$ has shown that aureomycin may be of value in the treatment of amobiasis. Because of the small number of cases they reported on, and the comparatively short period of parasitological examination after treatment, it is impossible, as yet, to judge the true value of this antibiotic as an anti-amœbic drug.

In an experimental amobic infection of rats $^{2}$, aureomycin produced a significant therapeutic effect at doses of 5-10 mgm. $/ \mathrm{kgm}$. Penicillin and streptomycin produced a similar effect at doses of $\mathbf{6 . 2 5}$ mgm. $/ \mathrm{kgm}$. and $2 \mathrm{mgm} . / \mathrm{kgm}$., respectively, whereas chloromycetin had no effect unless the comparatively high dose of $100 \mathrm{mgm} . / \mathrm{kgm}$. was used. Of these three latter antibiotics, only penicillin has been used in human amœbiasis, so far as can be ascertained from published literature. It was first used for treating refractory cases of acute amobic dysentery by Hargreaves in $1945^{3}$. Hargreaves's work, and that of others afterwards, showed the effect of penicillin to be due primarily to an action on secondary bacterial infection. Although a significant clinical improvement resulted from treatment with penicillin, Entamoeba histolytica persisted, and could be eradicated only by formal treatment with amœbicidal drugs.

McVay et al. make the important claim that treatment with aureomycin results not only in clinical improvement, but also in a disappearance of para. sites. This effect suggests an important point of difference from that of penicillin; namely, that aureomyein has some direct lethal action on the amœbæ. Unfortunately, it is difficult to investigate the direct action of drugs on Entamoba histolytica because of our inability to cultivate the parasite free from bacteria. At concentrations down to 1 in 90,000 , aureomycin prevents growth of a strain of $E$. histolytica in simple liquid medium, in the presence of a single species of bacterium $(B$. coli). Using another 